\section{Effect of 15\% Alcohol Dependence on Alveolar Bone Loss and TNF- $\alpha$ Secretion in Wistar Rats}

Marcius Comparsi Wagner, José Mariano da Rocha, Eduardo José Gaio, Juliano Cavagni, Vinícius Coelho Carrard, Cassiano Kuchenbecker Rösing
Department of Periodontology, UFRGS - Federal University of Rio Grande do Sul, Porto Alegre, RS, Brazil

Correspondence: Prof. Dr. Cassiano K. Rosing, Rua Dr. Valle, 433/701, 90560-010 Porto Alegre, RS, Brasil. Tel: +55-51-3308-5318. e-mail: ckrosing@hotmail.com

\begin{abstract}
The aim of the present study was to evaluate the effect of 15\% alcohol dependence on ligature-induced alveolar bone loss and TNF- $\alpha$ secretion in Wistar rats. Thirty-three male Wistar rats aged 45-60 days ( mean weight $=253 \mathrm{~g}$ ) were randomly allocated test or control groups. Test group $(n=18)$ received $15 \%$ alcohol as liquid intake and control group $(n=15)$ received water during the experimental period. TNF- $\alpha$ was analyzed by ELISA assay in 11 animals per group. After 14 days of alcohol/water intake, alcohol dependency was assessed and silk ligatures were placed around the left second upper molars. Ligature presence and body weight were checked weekly. After 40 days, animals were sacrificed and the maxillae were defleshed for morphometric analysis using standardized images. All animals in the test group displayed signs of alcohol dependency at day 14. No statistically significant differences in final body weight ( $334.83 \pm 21.38$ vs. $322.48 \pm 30.65 g, p=0.20)$ were observed between groups. In relation to alveolar bone loss, no statistically significant difference was observed among test and control groups both for ligated teeth $(0.76 \pm 0.06$ vs. $0.74 \pm 0.10 \mathrm{~mm}, \mathrm{p}=0.60)$ and unligated teeth $(0.41 \pm 0.16$ vs. $0.35 \pm 0.05 \mathrm{~mm}, \mathrm{p}=0.22)$. The TNF- $\alpha$ secretion also did not display statistically significant differences between test and control groups $(10.78 \pm 1.84$ vs. $12.13 \pm 2.11 \mathrm{pg} / \mathrm{mL}, \mathrm{p}=0.12)$. It may be concluded that $15 \%$ alcohol dependency was not capable to alter alveolar bone loss and TNF- $\alpha$ secretion in Wistar rats.
\end{abstract}

Key Words: periodontitis, rats, alcohol dependence, alveolar bone loss.

\section{Introduction}

The relationship between alcohol consumption and several chronic diseases has been reported as a U- or J-shaped curve attributed to a dose-related combination of beneficial and harmful effects. While alcoholism or alcohol abuse can lead to cardiovascular, liver and pancreatic diseases, light to moderate consumption of alcohol may display a protective effect (1-3). Several biological mechanisms can be involved in the pathogenesis or prevention of these chronic diseases, such as the modulation of some pro-inflammatory markers (e.g. IL-6 and TNF- $\alpha$ ) $(4,5)$. The drinking pattern can also impair or repair the immunological function by modulation of neutrophils, macrophages and T-cells $(6,7)$.

Periodontal diseases have an infectious-inflammatory nature and are associated mainly to gram-negative bacteria $(8,9)$. The relationship between alcohol consumption and periodontal diseases remains unclear in the literature. Similarly to the relationship with other chronic diseases, results from animal and human studies seem to report a $\mathrm{U}$ - or J-shaped curve $(4,10)$. However, there is no sense in the literature about what pattern of alcohol consumption is considered safe, beneficial or harmful. Studies in rats with high alcohol concentration (20\%) suggest that alcohol can have a destructive effect on the ligature-induced alveolar bone loss $(11,12)$. On the other hand, low alcohol concentration (5\%) seems to present a protective effect in spontaneous alveolar bone loss (13). Additionally, it has been demonstrated that moderate alcohol consumption is associated with lower levels of cytokines linked to periodontitis in humans (5).

Few studies have sought to clarify the relative role of alcohol dependence on periodontitis in humans and are scarce in animal models (14-16). Therefore, important questions remain regarding this issue. Among these, the role of alcohol dependence on pro-inflammatory cytokines and what is the concentration that could be attributed as beneficial or harmful to the periodontium. The aim of the present study is to evaluate the impact of alcohol consumption on the pathogenesis of periodontal diseases in rats. The hypothesis to be tested is that $15 \%$ alcohol dependence can alter both periodontal breakdown and TNF- $\alpha$ secretion in Wistar rats.

\section{Material and Methods Animals}

Thirty-five male Wistar rats aged 45-60 days with mean weight of $253 \pm 19.86 \mathrm{~g}$ were used in the present study. Animals were housed in cages with five animals at a temperature range from $18{ }^{\circ} \mathrm{C}$ to $20^{\circ} \mathrm{C}$ and a $12 \mathrm{~h}$ light 
and dark cycle. The Ethical Committee on Animals Use of the Federal University of Rio Grande do Sul, Brazil approved the experimental protocol (Protocol number 18979/10, September 14, 2010).

\section{Sample Size Calculations}

Sample size estimates were based on data from a previous study (11). A difference of $0.2 \mathrm{~mm}$ in alveolar bone loss was expected as significant. Considering alpha and beta errors of 0.05 and 0.10 respectively, a minimum number of 14 animals per group was considered necessary.

\section{Experimental Groups and Procedures}

Animals were randomly assigned to two groups stratified by weight. The control group $(n=15)$ was fed with a standard laboratory rat chow (Nuvilab CR1 ${ }^{\circledR}$; Nuvital Nutrientes SA, Colombo, PR, Brazil) and tap water ad libitum for 6 weeks. The test group $(n=20)$ received the same diet except for the water, which was replaced by a $15 \%$ ethylic alcohol solution (Vetec ${ }^{\oplus}$; Rio de Janeiro, RJ, Brazil) that was available ad libitum throughout the experiment. Prior to ligature placement, the test group was submitted to a 2-week period of 15\% alcohol intake. Two animals of the $\vec{s}$ test group were lost. The first died in the first week due to complications of alcohol intake and the second died in the day that the ligature was placed during the anesthesia. These deaths resulted in 15 animals for control and 18 animals for test group.

General anesthesia was performed by intramuscular administration of xylazine/ketamine $(10 \mathrm{mg} / \mathrm{kg}-1: 1)$.
Alveolar bone loss was induced by placement of 4.0 silk ligatures (Ethicon ${ }^{\oplus}$, Johnson \&t Johnson ${ }^{\circledast}$, São Paulo, SP, Brazil) around the maxillary right second molars. The contralateral tooth remained as intra-group control $(13,17)$. Animals were killed after 4 weeks of ligature placement. Figure 1 shows the flowchart of the study.

The liquid and solid intake was monitored during the study. Body weight and presence of ligature of the animals were evaluated weekly.

\section{Alcohol Dependence Test}

Prior to periodontal breakdown induction, animals from test and control groups were submitted to an alcohol dependence test $(18,19)$. Animals were exposed to a $14 \mathrm{~h}$ of alcohol/water abstinence. Next, they were removed from their cages and then were gently manipulated and placed in another cage with minimum light and noise. Physical signs of alcohol withdrawal were observed and recorded. Animals from control group were used as negative controls. The examiner was blinded to the groups. The signs observed were trembles in tail and body, jaw grind and hyperactivity.

\section{$T N F-\alpha$ Analysis}

TNF- $\alpha$ analysis was performed in a randomly selected subgroup sample (11 animals per group). Animals were killed by decapitation and immediately trunk blood collected and centrifuged for $5 \mathrm{~min}$ in $5000 \mathrm{xg}$ at room temperature. The levels of TNF- $\alpha$ in supernatants were determined using commercially available enzyme-linked immunosorbent assay (ELISA) kit for rats TNF- $\alpha$ (Uscn Life Science Inc.,

$15 \%$ Alcohol / Water consumption

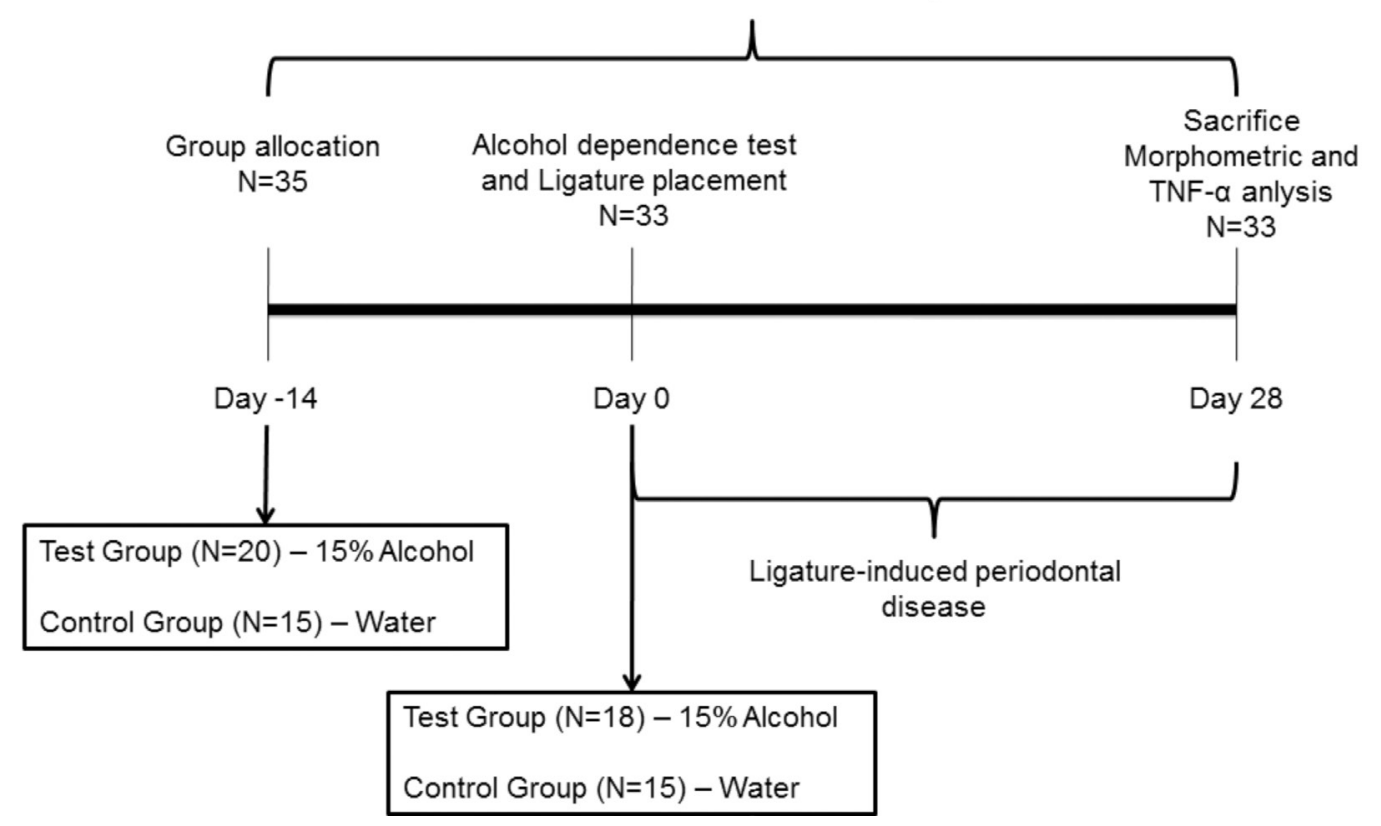

Figure 1. Study flowchart. 
Houston, TX, USA), according to manufacturer protocols. Samples were incubated on 96-well flat bottom plates previously coated with anti-TNF- $\alpha$ antibody for $2 \mathrm{~h}$ at 37 ${ }^{\circ} \mathrm{C}$. After this first incubation, a TNF biotin-conjugated antibody preparation specific for TNF- $\alpha$ was added to each well and incubated for $1 \mathrm{~h}$ and avidin-conjugated horseradish peroxidase for $30 \mathrm{~min}$ at $37^{\circ} \mathrm{C}$. The reactions were stopped with $150 \mathrm{~mL}$ of $1.0 \mathrm{M} \mathrm{H}_{2} \mathrm{SO}_{4}$ and ELISA reader measured the absorbencies at $490 \mathrm{~nm}$. The standard TNF- $\alpha$ curve was performed on each plate, ranging from 0 to $1.000 \mathrm{pg} / \mathrm{mL}$. The tests were performed in duplicate for each sample.

\section{Morphometric Analysis}

Following sacrifice, the right and left segments of the maxillae were defleshed in sodium hypochlorite with 8.5\% active chlorine (Mazzarollo ${ }^{\oplus}$ Gravatai, RS, Brazil) for $5 \mathrm{~h}$. After rinsing, the specimens were washed and dried. After that, maxillae were stained during 1 minute in $1 \%$ methylene blue to delineate the cementoenamel junction $(13,17)$.

Standardized digital pictures were taken from the buccal, palatal and proximal aspects of each specimen using a millimeter ruler and a Nikon D100 (Nikon ${ }^{\oplus}$, Ayuthaia, Thailand) camera coupled in a tripod and equipped with a $100 \mathrm{~mm}$ macro-lenses with minimal focal distance. Each specimen was placed with the occlusal surface parallel to the floor. Linear measurements were performed with Adobe Photoshop $\mathrm{CS}^{\oplus}{ }^{\oplus}$ software (Adobe Systems Inc., San Jose, CA, USA). Alveolar bone loss was defined as the distance between the cementoenamel junction and the alveolar bone crest. Buccal and palatal measurements were made at five points $(13,17)$. Next, in order to perform proximal measurements, removal of the first and third molars was necessary. After these procedures, measurements were made at three points in each proximal surface (20). For

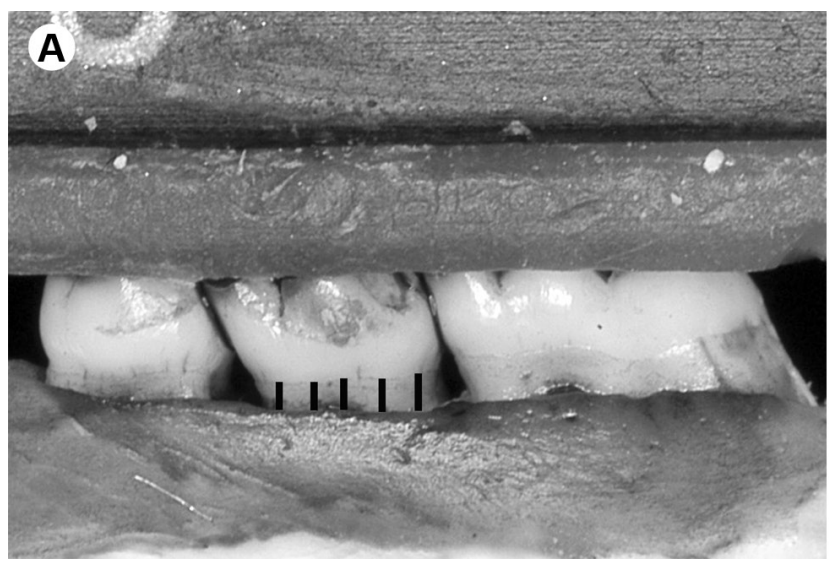

each surface, mean values were calculated and, following, a mean value for the tooth was generated. Figures 2 and 3 demonstrate the measurement points in teeth without (A) and with ligatures (B) in buccal and proximal areas, respectively.

The examiner was unaware of the group distribution as well as of the presence or absence of ligature. Measurements were converted into millimeters, utilizing a precision ruler as reference. Reproducibility was checked by re-analyzing the specimens within an one-week interval. Intraclass correlation coefficient (ICC) was 0.96 and 0.89 for buccal/ palatal and proximal surfaces, respectively.

\section{Statistical Analysis}

For each evaluated parameter normality was tested by means of Shapiro-Wilk analysis and the appropriate statistical test was selected according to this assumption. The rat was considered the unit of analysis in this study. All tests were performed by SPSS ${ }^{\oplus}$ version 17.0 (SPSS Inc.,
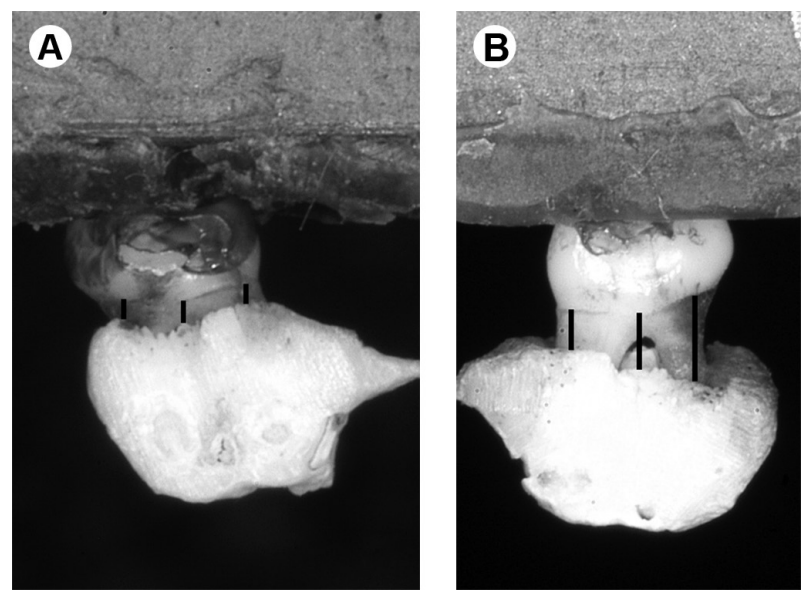

Figure 3. Demonstration of the measurement performed in teeth without (A) and with (B) ligatures in proximal area.



Figure 2. Demonstration of the measurement performed in teeth without (A) and with (B) ligatures in the buccal area. 
Chicago, IL, USA). Mean body weight throughout the study was calculated and compared by repeated measurements ANOVA. Intragroup mean body weight, alveolar bone loss and the TNF- $\alpha$ secretion were compared by independent samples $t$-test.

\section{Results}

At day 0 , animals were tested for alcohol dependence. All animals from the test group demonstrated signs of alcohol dependence (trembles in tail and body, jaw grind and hyperactivity) whereas this characteristic was not detected in animals from control group.

The body weight of the animals was monitored throughout the study. Statistically significant differences in mean body weight were observed between control and test groups at days $7(p=0.01)$ and $28(p=0.04)$. During the entire study, higher values of body weight were observed in the control group (Fig. 4). Body weight increased both in test and control groups, with statistically significant differences being detected by repeated measures ANOVA within each group along the study when compared to day $-14(\mathrm{p}<0.00)$.

During the experimental period, animals from the test $\vec{s}$ group had a mean daily alcohol consumption of 21.69 $\mathrm{mL}$. Figure 5 shows the evolution of alcohol consumption for test group from day 0 to day 28 (repeated measures ANOVA). Animals from test group presented less daily alcohol consumption in day $14(\mathrm{p}=0.01)$ and day $21(\mathrm{p}=0.03)$

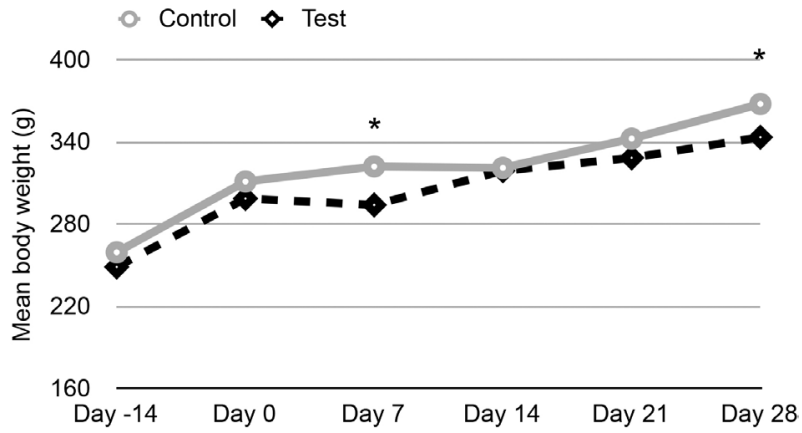

Figure 4. Mean body weight (grams) for control and test groups throughout the study. *Independent samples $t$-test $(\mathrm{p}<0.05)$. compared to day 0 . At day 28 , no differences were observed compared to day $0(\mathrm{p}=0.08)$.

The main outcome of the present study is periodontal breakdown. Table 1 shows the mean alveolar bone loss in teeth with and without ligature in control and test groups. Data are demonstrated for each tooth surface and also combining all tooth surfaces. Statistically significant differences between groups were observed only in the distal aspect of teeth with ligatures $(p=0.02)$. It can be observed that teeth without ligature present approximately $40 \%$ less periodontal breakdown than teeth with ligatures.

TNF- $\alpha$ secretion analysis (mean \pm SD) showed no statistically significant differences between control and test group $(12.13 \pm 2.11$ and $10.78 \pm 1.84 \mathrm{pg} / \mathrm{mL})$ respectively, $(p=0.12)$.

\section{Discussion}

This study analyzed the influence of 15\% alcohol dependence on alveolar bone destruction and TNF- $\alpha$ secretion in male Wistar rats. No differences in the mean alveolar bone loss were found in this study, when the whole tooth is considered. Previously, studies showed that a low concentration of alcohol consumption (5\%) had a protective effect on spontaneous periodontitis (13) while a higher concentration of alcohol consumption (20\%) had a destructive effect on the periodontium (11). Similarly, in epidemiologic studies, a moderate consumption of alcohol can have a protective effect for periodontal disease while a

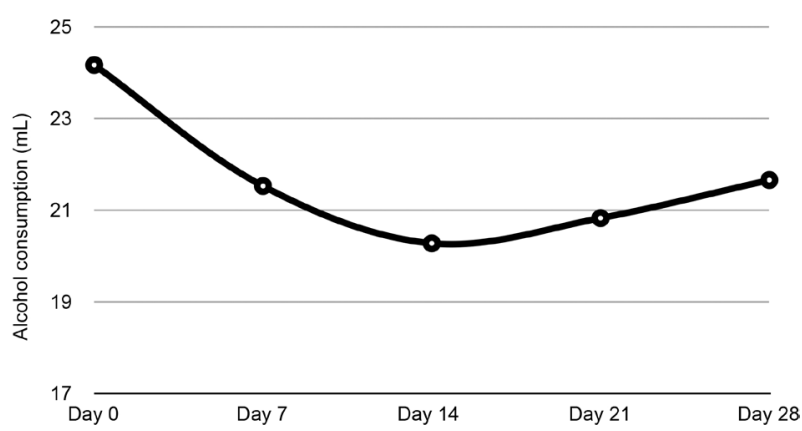

Figure 5. Mean daily alcohol consumption (milliliters) per animal in the test group from day 0 to 28 .

Table 1. Mean alveolar bone loss $(\mathrm{mm}( \pm \mathrm{SD}))$ in teeth with and without ligatures in control and test groups

\begin{tabular}{|c|c|c|c|c|c|c|c|c|c|c|}
\hline \multirow{2}{*}{ Group } & \multicolumn{5}{|c|}{ Teeth with ligature } & \multicolumn{5}{|c|}{ Teeth without ligature } \\
\hline & Mesial & Distal & Palatal & Buccal & Total & Mesial & Distal & Palatal & Buccal & Total \\
\hline Control & $0.86( \pm 0.15)$ & $0.81( \pm 0.10)$ & $0.69( \pm 0.13)$ & $0.89( \pm 0.15)$ & $0.76( \pm 0.06)$ & $0.50( \pm 0.16)$ & $0.49( \pm 0.56)$ & $0.46( \pm 0.10)$ & $0.29( \pm 0.05)$ & $0.41( \pm 0.16)$ \\
\hline Test & $0.89( \pm 0.16)$ & $0.69( \pm 0.16)$ & $0.69( \pm 0.12)$ & $0.84( \pm 0.20)$ & $0.74( \pm 0.10)$ & $0.48( \pm 0.12)$ & $0.31( \pm 0.12)$ & $0.42( \pm 0.04)$ & $0.26( \pm 0.03)$ & $0.35( \pm 0.05)$ \\
\hline $\mathrm{p}^{*}$ & 0.58 & 0.02 & 0.96 & 0.44 & 0.60 & 0.80 & 0.19 & 0.17 & 0.10 & 0.22 \\
\hline
\end{tabular}

*Independent samples t-test. 
heavy consumption is associated with a destructive pattern (10). These evidences seem to confirm a U- or J-shaped curve relationship between alcohol consumption and periodontal disease, similarly to what happens in relationship with cardiovascular diseases and the consumption of alcohol. In this sense, it would be interesting to determine the cut-off point of the curve in order to better understand this relationship.

One interesting finding of the present study is that when surfaces are analyzed separately, considering the distal aspects, a statistically significant difference was detected among groups, demonstrating, for these surfaces, a protective effect of alcohol. This is in line with other studies, and this result should not be ruled out. Therefore, a potential protective effect was demonstrated in this study. The findings of the present study seem mimic low/ moderate alcohol consumption.

Low/moderate alcohol consumption has been considered a preventive factor by reducing the risk for myocardial infarction, stroke and other systemic disorders. However, high alcohol consumption poses a higher risk of myocardial infarction. It is not clear which kind of beverage or what is the concentration of alcohol that would have a preventive effect and why low/moderate regular alcohol intake should be beneficial to humans $(3,21)$. A drinking pattern of 3-4 times per week has been found inversely associated with the risk of myocardial infraction in men (1).

Alcohol can have an anti-bacterial role, however the potential effect of regular low/moderate alcohol intake on the oral microbiota has not been fully demonstrated. Drinking patterns have been assessed and seem to alter the oral bacterial profile. Consumption for at least two years of coffee or red wine is associated with a reduction of the frequency of anaerobes in supra- and subgingival plaque samples compared to water drinkers (22). Studies on alcohol dependence and alcohol consumption on periodontal diseases are controversial. While some studies reveal increased risk with increasing daily consumption of alcohol, other studies verified no association $(10,16,23)$. If alcohol consumption reduces the bacterial load in the oral cavity, this effect would be observed on the prevalence of infectious diseases in the mouth.

Pathogenesis of periodontal breakdown has been widely studied in rat models. Previous studies evaluated alveolar bone loss only in buccal and palatal surfaces $(11,13,17)$. In the present study a new approach was conducted in order to measure proximal surfaces. Therefore, first and third molars were gently removed followed by standardized pictures of the mesial and distal surfaces, allowing the same as the measurements performed in buccal and palatal surfaces. It is important to emphasize that a positive correlation between alveolar bone loss in buccal/palatal and proximal surfaces has been shown, which improves the use of this new approach to quantify alveolar bone loss in Wistar rats (20).

Several mechanisms have been suggested by which alcohol intake could lower the risk of inflammatory diseases, such as beneficial effects on C-reactive protein, IL-6, and TNF- $\alpha(5,24,25)$. The present study showed no differences in TNF- $\alpha$ levels between groups, although there is a reduction of approximately $18 \%$ in production of TNF- $\alpha$ in the test group. This mean percent reduction is very similar to human studies that found significant results between groups exposed or not to alcohol $(5,24)$.

Adverse effects of high consumption of alcohol on human health are well known described in the literature. One possible explanation is that this seems to occur because the episodic consumption of large amounts of alcohol has been associated with increase of the host susceptibility to infections. This effect has biological plausibility to clarify its influence on periodontal diseases, since the high consumption of alcohol can cause damage in neutrophils, macrophages and function of $T$ cells, increasing the likelihood of infections (6).

The findings of the present study are challenging, with possibilities of better understanding the relationship between alcohol consumption and periodontal breakdown. The possible biological mechanisms should be further understood and longitudinal follow-up is required. It can be concluded that 15\% alcohol consumption generated dependence, however was not able to consistently modify alveolar bone loss and TNF- $\alpha$ secretion in male Wistar rats.

\section{Resumo}

0 objetivo do presente estudo foi avaliar o efeito da dependência de álcool a $15 \%$ sobre a perda óssea alveolar induzida e secreção de TNF- $\alpha$ em ratos Wistar. Trinta e três ratos wistar com idade entre 45 e 60 dias (peso médio $=253 \mathrm{~g}$ ) foram alocados aleatoriamente para o grupo teste ou controle. 0 grupo teste $(n=18)$ recebeu álcool a 15\% como ingestão liquida e o grupo controle $(n=15)$ recebeu água durante o período experimental. TNF- $\alpha$ foi analisado por meio de ELISA em 11 animais por grupo. Após 14 dias de ingestão de álcool/água a dependência do álcool foi determinada e ligaduras de seda foram colocadas ao redor dos segundos molares superiores esquerdos. A presença das ligaduras e o peso corporal foram verificadas semanalmente. Depois de 40 dias os animais foram sacrificados e as maxilas foram preparadas para análise morfométrica em fotografias estandardizadas. Todos os animais do grupo teste apresentaram sinais de dependência de álcool no dia 14. Não foram observadas diferenças estatisticamente significativas no peso corporal final entre os grupos $(334,83 \pm 21,38$ vs. $322,48 \pm 30,65$ gramas, $p=0,20$ ) Em relação a perda óssea alveolar, não foram observadas diferenças estatisticamente significativas entre os grupos teste e controle tanto para dentes com $(0,76 \pm 0,06$ vs. $0,74 \pm 0,10 \mathrm{~mm}, p=0,60)$ como para dentes sem ligadura $(0,41 \pm 0,16 \mathrm{vs}$. $0,35 \pm 0,05 \mathrm{~mm}, p=0,22)$. A secreção de TNF- $\alpha$ também não demonstrou diferenças estatisticamente significativas entre os grupos teste e controle $(10,78 \pm 1,84$ vs. $12,13 \pm 2,11 \mathrm{pg} / \mathrm{mL}, \mathrm{p}=0,12)$. Pode-se concluir que a dependência de álcool a 15\% não foi capaz de alterar a perda óssea alveolar e a secreção de TNF- $\alpha$ em ratos Wistar. 


\section{Acknowledgements}

The authors thank Dr. Marcelo Ekman Ribas for his assistance during the experimental phase of the study.

\section{References}

1. Mukamal KJ, Conigrave KM, Mittleman MA, Camargo Jr CA, Stampfer MJ, Willett WC, et al.. Roles of drinking pattern and type of alcohol consumed in coronary heart disease in men. $\mathrm{N}$ Engl J Med 2003;348:109-118.

2. Elkind MS, Sciacca R, Boden-Albala B, Rundek T, Paik MC, Sacco RL. Moderate alcohol consumption reduces risk of ischemic stroke: the Northern Manhattan Study. Stroke 2006;37:13-19.

3. Costanzo S, Di Castelnuovo A, Donati MB, lacoviello $L$, de Gaetano G. Wine, beer or spirit drinking in relation to fatal and non-fatal cardiovascular events: a meta-analysis. Eur J Epidemiol 2011;26:833850 .

4. Diaz LE, Montero A, Gonzalez-Gross M, Vallejo Al, Romeo J, Marcos A. Influence of alcohol consumption on immunological status: a review. Eur J Clin Nutr 2002;56 Suppl 3:S50-53.

5. Marques-Vidal $P$, Bochud $M$, Bastardot $F$, von Kanel $R$, Ferrero $F$, Paccaud $F$, et al.. Associations between alcohol consumption and selected cytokines in a Swiss population-based sample (CoLaus study). Atherosclerosis 2012;222:245-250.

6. Szabo G. Consequences of alcohol consumption on host defence. Alcohol 1999;34:830-841.

7. Romeo J, Wärnberg J, Nova E, Díaz LE, Gómez-Martinez $S$, Marcos A Moderate alcohol consumption and the immune system: a review. $\mathrm{Br} J$ Nutr 2007;98 Suppl 1:S111-115.

8. Socransky SS, Haffajee AD, Cugini MA, Smith C, Kent RL Jr. Microbial complexes in subgingival plaque. J Clin Periodontol. 1998;25:134-144.

9. Socransky SS, Haffajee AD. Periodontal microbial ecology. Periodontol 2000 2005;38:135-187.

10. Bouchard P, Boutouyrie P, Mattout C, Bourgeois D. Risk assessment for severe clinical attachment loss in an adult population. J Periodontol 2006;77:479-489.

11. Souza DM, Ricardo LH, Prado MA, Prado FA, Rocha RF. The effect of alcohol consumption on periodontal bone support in experimental periodontitis in rats. J Appl Oral Sci 2006;14:443-447.

12. Souza DM, Ricardo LH, Kantorski KZ, Rocha RF. Influence of alcohol consumption on alveolar bone level associated with ligature-induced periodontitis in rats. Braz Oral Res 2009;23:326-332.

13. Liberman DN, Pilau RM, Gaio EJ, Orlandini LF, Rosing CK. Low concentration alcohol intake may inhibit spontaneous alveolar bone loss in Wistar rats. Arch Oral Biol 2011;56:109-113.

14. Enberg N, Wolf J, Ainamo A, Alho H, Heinala P, Lenander-Lumikari M. Dental diseases and loss of teeth in a group of Finnish alcoholics: a radiological study. Acta Odontol Scand 2001;59:341-347.

15. Amaral CS, Luiz RR, Leão AT. The relationship between alcohol dependence and periodontal disease. J Periodontol 2008;79:993-998.

16. Amaral CS, Vettore MV, Leão A. The relationship of alcohol dependence and alcohol consumption with periodontitis: a systematic review. J Dent 2009;37:643-651.

17. Fernandes MI, Gaio EJ, Oppermann RV, Rados PV, Rosing CK. Comparison of histometric and morphometric analyses of bone height in ligature-induced periodontitis in rats. Braz Oral Res 2007;21:216221.

18. Majchrowicz E. Reversal in central neural system function during ethanol withdrawal in humans and experimental animals. Fed Proc 1981:40:2065-2072.

19. Chung CS, Wang J, Wehman M, Rhoads DE. Severity of alcohol withdrawal symptoms depends on developmental stage of Long-Evans rats. Pharmacol Biochem Behav 2008;89:137-144.

20. Azambuja CB, Cavagni J, Wagner MC, Gaio EJ, Rösing CK. Correlation analysis of alveolar bone loss in buccal/palatal and proximal surfaces in rats. Braz Oral Res 2012;26:571-577.

21. Di Castelnuovo A, Rotondo S, lacoviello L, Donati MB, De Gaetano G. Meta-analysis of wine and beer consumption in relation to vascular risk. Circulation 2002;105:2836-2844.

22. Signoretto C, Bianchi F, Bulacchini G, Sivieri F, Spratt D, Canepari $P$. Drinking habits are associated with changes in the dental plaque microbial community. J Clin Microbiol. 2010;48: 347-356.

23. Tezal M, Grossi SG, Ho AW, Genco RJ. Alcohol consumption and periodontal disease. The Third National Health and Nutrition Examination Survey. J Clin Periodontol 2004;31:484-488.

24. Pai JK, Hankinson SE, Thadhani R, Rifai N, Pischon T, Rimm EB. Moderate alcohol consumption and lower levels of inflammatory markers in US men and women. Atherosclerosis 2006;186:113-120.

25. Imhof $A$, Froehlich $M$, Brenner $H$, Boeing $H$, Pepys MB, Koenig W. Effect of alcohol consumption on systemic markers of inflammation. Lancet 2001;357:763-767 